\title{
Treatment of Infected Primary Teeth using Modified Antibiotic Paste
}

\author{
Sherin Aly Hussein ${ }^{1,2 *}$ and Arwa Namnakani ${ }^{3}$ \\ ${ }^{1}$ Pediatric Dentistry Specialist, Ohud Dental Center, Ohud Hospital, Saudi Arabia \\ ${ }^{2} \mathrm{MSc}$ in Pediatric Dentistry, Ain Shams University, Cairo, Egypt \\ ${ }^{3}$ College of Dentistry, Taibah University, Saudi Arabia \\ *Corresponding author: Sherin Aly Hussein, Pediatric Dentistry Specialist, Ohud Dental Center, Ohud Hospital, Madina, Saudi Arabia \\ MSc in Pediatric Dentistry, Ain Shams University, Cairo, Egypt
}

\begin{abstract}
Objectives: Treatment of pulpectomized primary molars with chronic infection using a mixture of three antibiotics: Metronidazole, Ciprofloxacin, and Doxycycline mixed with Macrogol or Propylene Glycol (modified 3MIX-MP) as an intracanal medicament before the complete cleaning and shaping and obturation.

Study design: A 7 years old child with infected primary molar came to our clinic for treatment. A detailed medical history and drug allergy were taken. Ciprofloxacin (500 mg), Metronidazole (500mg) and Doxycycline (100mg) tablets divided in the proportion of 1:3:3 (one part of Ciprofloxacin, three parts of Metronidazole, and three parts of Doxycycline) and mixed with propylene glycol to form an ointment. Biomechanical preparation was done. The modified 3MIX-MP paste placed in the pulp chamber then temporary filling. The patient was recalled after 2 weeks. The tooth was obturated and restored then a stainless-steel crown placed. Then reevaluated at $3^{\text {rd }}, 6^{\text {th }}$, and $12^{\text {th }}$ months.

Results: Excellent clinical and radiographic success when compared to conventional pulpectomy and non-instrumentational lesion sterilization tissue repair therapy.

Conclusion: Treatment of Primary molar with modified 3MIX-MP, followed by instrumentation and obturation provided excellent clinical and radiographic success when compared to non-instrumentational lesion sterilization tissue repair therapy.
\end{abstract}

Keywords: Pulp infection; Pulpectomy; Modified antibiotic paste; Primary molars; Chronic, infected pulp; Modified 3 MIX-MP; Pulpectomy; Triple antibiotic paste; Primary teeth

\section{Introduction}

The first topical antibiotic introduced to endodontics was Grossman's polyantibiotic paste in 1951, later many topical antibiotics have been introduced with varying combinations, few of those include Septomixine forte; PBSC (Combination of Penicillin, Bacitracin, Streptomycin and Caprylate sodium), and Clindamycin. However, none of these combinations has proven to be $100 \%$ successful in eliminating all the bacterial strains from the root canal system [1-5].

\section{Materials and Methods}

A child aged 7 years old with chronic infection related to the lower left primary molar came to our clinic for treatment of the infected molar (Figure 1). Treatment was explained to the parents and written informed consent was taken from parents before start of the study. A detailed medical history and previous illness with a history of drug allergy were taken from the parents, then the mentioned primary molar was diagnosed clinically, the molar was badly decayed with signs of chronic infection such as: gingival swelling and tenderness to percussion. A radiographic examination was done and a per radicular radiolucency was found, with no excessive root resorption. Commercially available chemotherapeutic agents such as Ciprofloxacin (500mg) (Omacip, NPI Pharma, Oman), Metronidazole (500mg) (Anazol, JPI, Saudi Arabia), and Doxycycline (100mg) (Tabocine, TPMC, Tabuk) tablets were obtained [6,7], then these tablets were crushed into fine powder using sterile porcelain mortar and pestle. These powdered drugs were transferred into three separate sterile glass containers, capped tightly and stored in the refrigerator until its use. Just 
before use, each powdered drug was divided in the proportion of 1:3:3 (one part of Ciprofloxacin, three parts of Metronidazole, and three parts of Doxycycline) and were mixed with propylene glycol and polyethylene glycol to form an ointment. Reddy GA et al. Trairatvorakul and Detsomboonrat, Jaya et al., Cruz et al. also followed the similar protocol of preparation of 3MIX antibiotic paste [8-11].

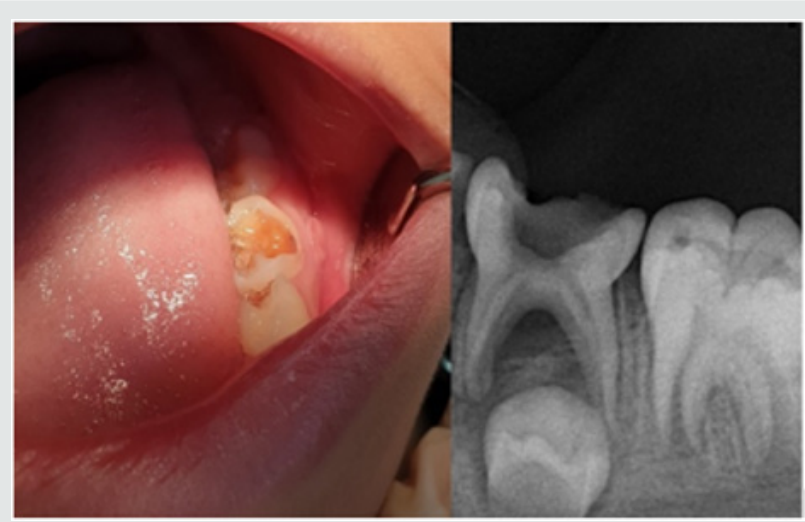

Figure 1: Preoperative illustration.

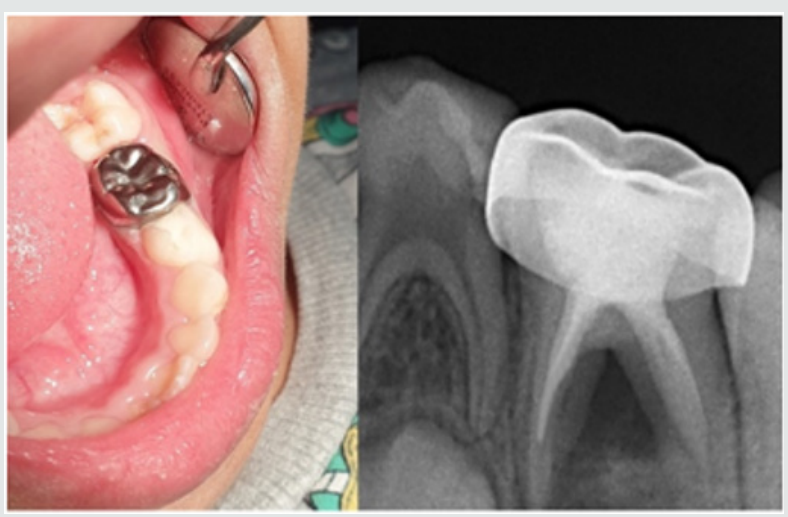

Figure 2: Postoperative illustration.

Preoperative clinical and radiographical signs and symptoms were recorded. The tooth was anesthetized using 2\% Xylocaine with 1:80,000 adrenalin and isolated with rubber dam. Access opening was performed using round bur, Biomechanical preparation was done using $\mathrm{k}$ files from size $10-25$. The root canals were chemically cleaned with $1 \%$ sodium hypochlorite solution and dried with paper points. The 3MIX-MP paste placed in the pulp chamber and pressed with dampened cotton pellet and temporized with Cavit. The patient was recalled after 2 weeks for evaluation. The tooth was obturated with reinforced zinc oxide eugenol (IRM, Dentsply) using lentulo spirals. Then restored with glass ionomer restorative material (Riva self-cure, SDI) and reinforced by placing stainless steel crowns (Figure 2). Further, the treated tooth was reevaluated both clinically and radiographically at $3^{\text {rd }}, 6^{\text {th }}$, and $12^{\text {th }}$ months intervals postoperatively (Figure 3). At the time of revisits, the tooth was examined clinically for any signs of failure that includes a report of spontaneous pain, presence of swelling, sinus tract and mobility. Radiographic evaluation was done to check the radiolucency and signs of resorption. The tooth was asymptomatic without pain, swelling, sinus tract and mobility also there was no increase in furcation radiolucency or development of root resorption which is abnormal for the age of the child.

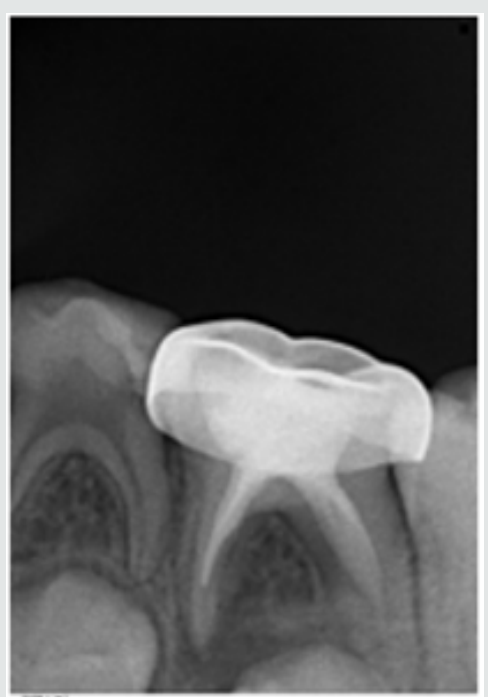

Figure 3: 12 months Follow up.

\section{Results}

Excellent clinical and radiographic success when compared to conventional pulpectomy and non-instrumentational lesion sterilization tissue repair therapy.

\section{Discussion}

This study was approved by "Research Ethics Committee, Taibah University, College of Dentistry, TU CD-REC". The concept of Non-Instrumentation Endodontic Therapy introduced by Niigata university school of dentistry; Japan has gained reputation as it proved to attain $100 \%$ sterility in the root canal system [1215]. They recommended a technique similar to pulpotomy where debriding only the pulp chamber of chronically infected primary teeth and placing medicament (ciprofloxacin, metronidazole, and minocycline) near the root orifice without preparing the radicular portion. Cruz et al. suggested vehicles such as macrogol and propylene glycol (3MIX-MP) and demonstrated that these vehicles will carry the medicament deep into the dentinal tubules, thus aid in effective eradication of bacteria [11]. Metronidazole (Nitroimidazole compound) due toits wide spectrum of antibacterial action against anaerobes (Ingham et al. 1975) gained importance as the $1^{\text {st }}$ choice drug for triple antibiotic paste preparation $[16,17]$. Metronidazole binds to the DNA and disrupts its helical structure and thus leads to rapid cell death. However, metronidazole even at higher concentrations could not eradicate all the bacteria thus indicating the necessity of some additional drugs to sterilize these lesions [15]. The two other antibacterial drugs, i.e. ciprofloxacin, and minocycline, in addition to metronidazole (3MIX) were added in an effort to eliminate all bacteria $[8,10,15,18]$. The $2^{\text {nd }}$ choice of drug ciprofloxacin is a synthetic fluoroquinolone with rapid bactericidal action. It inhibits the enzyme DNA gyrase of bacteria. It exhibits very potent activity against Gram-negative bacteria but very limited activity against Gram-positive bacteria. Most of the 
anaerobic bacteria are resistant to ciprofloxacin. Hence, it is often combined with metronidazole in treating mixed infections. The 3rd choice of drug was minocycline. It is a semisynthetic derivative of tetracycline, primarily bacteriostatic, inhibiting protein synthesis by binding to $30 \mathrm{~S}$ ribosomes in susceptible organisms and exhibits broad spectrum of activity against Gram-positive and Gramnegative microorganisms [3].

In our present study we replaced Minocycline with Doxycycline due to the difficulty in obtaining Minocycline, and before using the Doxycycline as a replacement we have done further searches for previous studies to ensure that both medications have the same effect and this replacement will not affect the efficacy of the mentioned mix. The already done studies concerning the difference between both Doxycycline and Minocycline revealed that still no statistically significant differences had been demonstrated in clinical trials when comparing Minocycline with Doxycycline, and investigators had concluded that both are equally effective. And they differ in their adverse event profile [19]. Considerably fewer adverse effects have been reported for Doxycycline than Minocycline; the adverse effects for Minocycline are 5 times more common than for Doxycycline [19]. We have followed the same protocol of Reddy GA et al. of extirpation of both necrotic coronal as well as all accessible radicular pulp tissue and then complete obturation, which is reported successful clinically over 16th month follow-up [9]. Although the previous studies have demonstrated that the LSTR (Lesion Sterilization Tissue Repair) technique as one of the successful techniques for management of chronically infected primary teeth, the controversies aroused about the duration of therapeutic activity of the medicament and leaving the infected material in the radicular region. So that the present study planned where in treated tooth were revisited after 2 weeks for medicament removal and obturation.

\section{Conclusion}

All the primary teeth with chronic infection which were treated using modified 3MIX-MP, followed by the instrumentation and obturation provided excellent clinical and radiographic success when compared to conventional pulpectomy and noninstrumentational lesion sterilization tissue repair therapy.

\section{References}

1. Ingle JI, Bakland LK (2002) Endodontics. (5 $5^{\text {th }}$ edn), Hamilton, Ontario, Elsevier, Canada, USA.

2. Abbot PV, Hume WR, Pearman JW (1990) Antibiotics and endodontics. Aust Dent J 35: 50-60.
3. Grossman LI (1972) Sterilization of infeted root canals. JADA 85: 900905.

4. Akpata ES (1974) Total viable count of microorganisms in the infected dental pulp. J Dent Res 53: 1330-1333.

5. Mata E, Koren LZ, Morse DR, Senai IH (1985) Prophylactic use of pencillin $\mathrm{V}$ in teeth with necrotic pulps and asymptomatic peripheral radiolucencies. Oral Surg 60: 201-207.

6. Valentín (2009) Clinical, Cosmetic and Investigational Dermatology, Dove Medical Press Ltd 2: 129-140.

7. Valentín S, Morales A, Sánchez JL, Rivera A (2009) Safety and efficacy of doxycycline in the treatment of rosacea. Clin Cosmet Investig Dermatol 2: $129-140$.

8. Trairatvorakul C, Detsomboonrat P (2012) Success rates of a mixture of ciprofloxacin, metronidazole, and minocycline antibiotics used in the non-instrumentation endodontic treatment of mandibular primary molars with carious pulpal involvement. Int J Paediatr Dent 22: 217-227.

9. Reddy GA, Sridevi E, Sai Sankar AJ, Pranitha K, Pratap Gowd MJS, et al. (2017) Endodontic treatment of chronically infected primary teeth using triple antibiotic paste: An in vivo study. J Conserv Dent $20(6)$ : 405-410.

10. Jaya AR, Praveen P, Anantharaj A, Venkataraghavan K, Rani PS (2012) In vivo evaluation of lesion sterilization and tissue repair in primary teeth pulp therapy using two antibiotic drug combinations. J Clin Pediatr Dent 37: 189-191.

11. Cruz EV, Kota K, Huque J, Iwaku M, Hoshino E (2002) Penetration of propylene glycol into dentine. Int Endod J 35: 330-336.

12. Nakornchai S, Banditsing P, Visetratana N (2010) Clinical evaluation of $3 \mathrm{Mix}$ and vitapex as treatment options for pulpally involved primary molars. Int J Paediatr Dent 20: 214-221.

13. Takushige T, Cruz EV, Asgor Moral A, Hoshino E (2004) Endodontic treatment of primary teeth using a combination of antibacterial drugs. Int Endod J 37: 132-138.

14. Hoshino E, Kurihara Ando N, Sato I, Uematsu H, Sato M, et al. (1996) In vitro antibacterial susceptibility of bacteria taken from infected root dentine to a mixture of ciprofloxacin, metronidazole and minocycline. Int Endod J 29: 125-130.

15. Divya S, Retnakumari N (2014) Lesion sterilisation and tissue repair in primary teeth with periapical pathosis - A case series. IOSR J Dent Med Sci 13: 7-11.

16. Hoshino E, Iwaku M, Sato M, Ando N, Kota K (1989) Bactericidal efficacy of metronidazole against bacteria of human carious dentin in vivo. Caries Res 23: 78-80.

17. Hoshino E, Kota K, Sato M, Iwaku M (1988) Bactericidal efficacy of metronidazole against bacteria of human carious dentin in vivo. Caries Res 22: 280-282.

18. Windley W, Teixeira F, Levin L, Sigurdsson A, Trope M (2005) Disinfection of immature teeth with a triple antibiotic paste. J Endod 31: 439-443.

19. Smith K, Leyden JJ (2005) Safety of doxycycline and minocycline: a systematic review. Clin Ther 27: 1329-1342. 
This work is licensed under Creative Commons Attribution 4.0 License

To Submit Your Article Click Here: Submit Article

DOI: $10.32474 /$ IPDOAJ.2019.03.000163

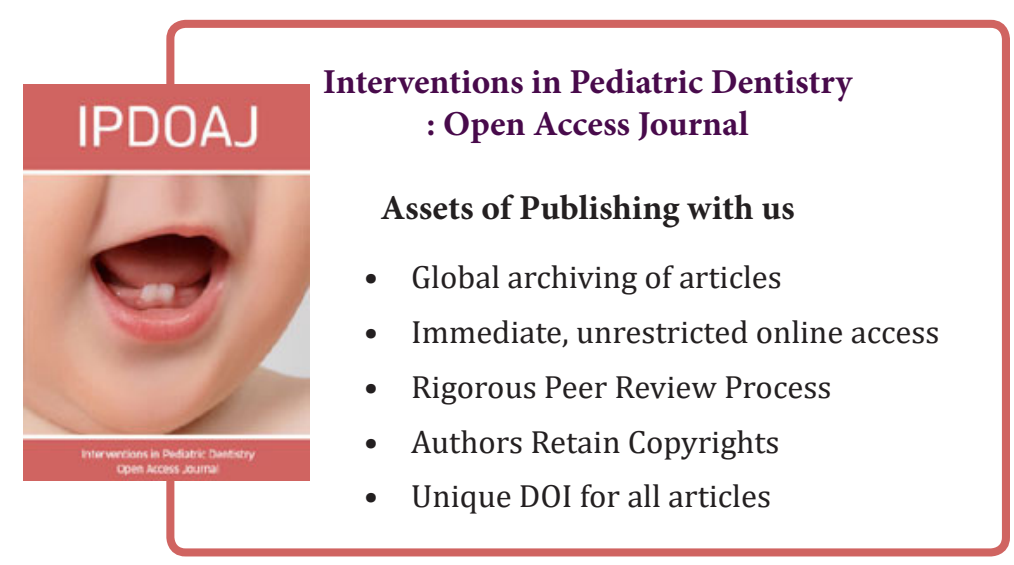

